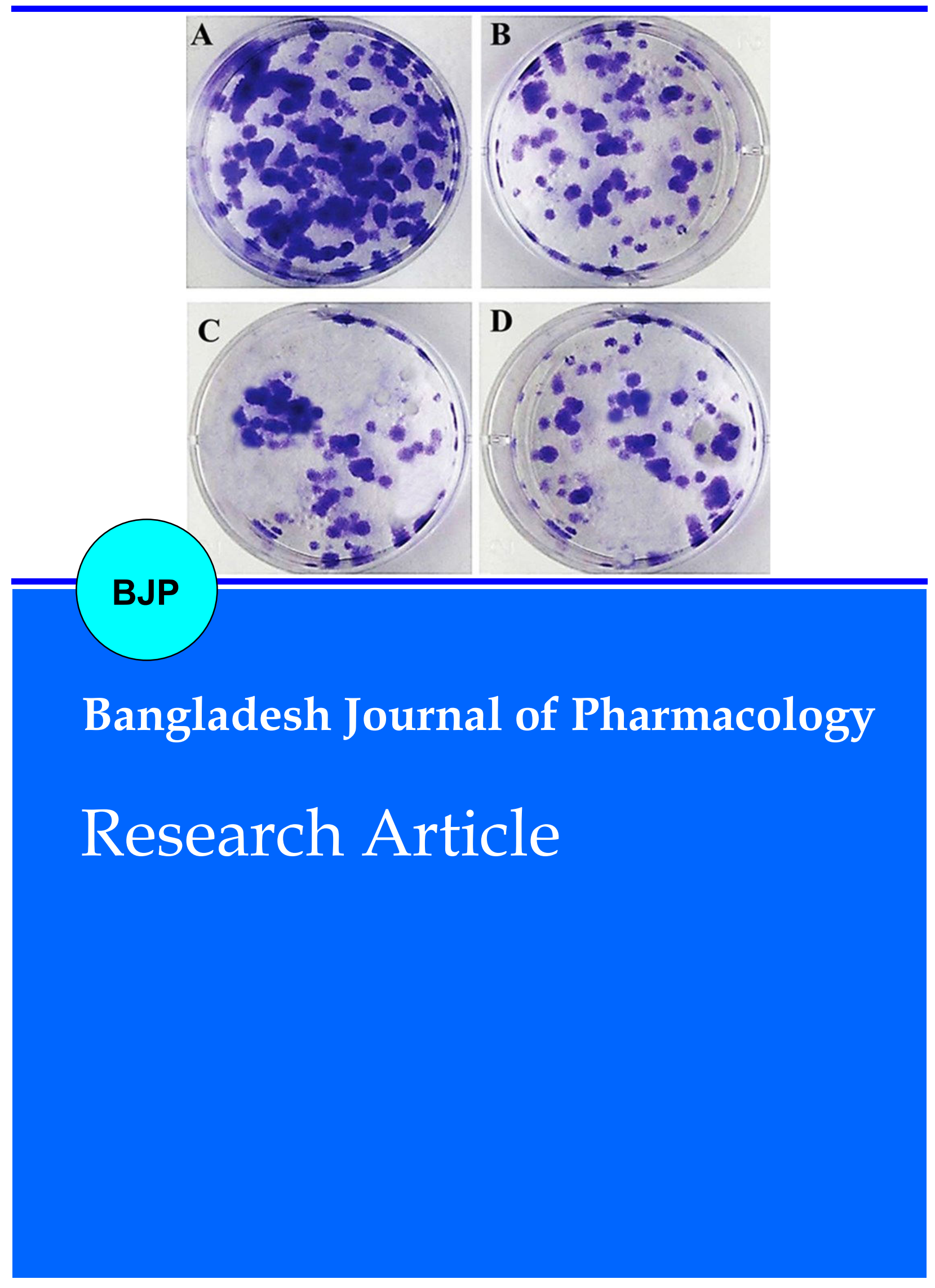


Abstracted/indexed in Academic Search Complete, Asia Journals Online, Bangladesh Journals Online, Biological Abstracts, BIOSIS Previews, CAB Abstracts, Current Abstracts, EMBASE/Excerpta Medica, Google Scholar, HINARI (WHO), International Pharmaceutical Abstracts, Open J-gate, Science Citation Index Expanded, SCOPUS and Social Sciences Citation Index

ISSN: $1991-0088$

\title{
5-Methoxyhydnocarpin shows selective anti-cancer effects and induces apoptosis in THP-1 human leukemia cancer cells via mitochondrial disruption, suppression of cell migration and invasion and cell cycle arrest
}

\author{
Xiao-Yan Xu, Hui-Rui Wang, Shu-Li Guo, Bo Li and Tao Lv \\ Department of Hematology, Luoyang Central Hospital Affiliated to Zhengzhou University, Luoyang, Henan 471-000, \\ China.
}

\begin{tabular}{|c|c|}
\hline \multicolumn{2}{|l|}{ Article Info } \\
\hline & 7 Febru \\
\hline & \\
\hline Available Online: & \\
\hline \multicolumn{2}{|c|}{$\begin{array}{l}\text { DOI: } 10.3329 / \text { bjp.v11i3.26767 } \\
\text { Cite this article: } \\
\text { Xu XY, Wang HR, Guo SL, Li B, Lv T. } \\
\text { 5-Methoxyhydnocarpin shows selec- } \\
\text { tive anti-cancer effects and induces } \\
\text { apoptosis in THP-1 human leukemia } \\
\text { cancer cells via mitochondrial disrup- } \\
\text { tion, suppression of cell migration } \\
\text { and invasion and cell cycle arrest. } \\
\text { Bangladesh J Pharmacol. 2016; 11: } 652 \\
-60 \text {. }\end{array}$} \\
\hline
\end{tabular}

\begin{abstract}
The primary objective of the current investigation was to study the anti-tumor effects of 5-methoxyhydnocarpin in THP-1 human leukemia cells along with evaluating its effects on apoptotic induction, cancer cell migration and cell cycle phase distribution. MTT cell viability assay revealed the cell cytotoxic effects while as clonogenic assay revealed the effects of the compound on colony formation tendency. Phase contrast microscopy revealed the effects on cell morphology while as its effects on cell cycle and apoptosis induction were evaluated by flow cytometer. Results showed that 5-methoxyhydnocarpin induced both anchorage-dependent and anchorage-independent cytotoxic effects in THP-1 cells. 5-Methoxyhydnocarpin-treated cells exhibited significant changes in cell morphology. Flow cytometry experiment indicated that 5-methoxyhydnocarpin led to sub-G1 cell cycle arrest and also led to early and late apoptosis.
\end{abstract}

\section{Introduction}

Cancer is the second most leading cause of mortality across the globe after the cardiovascular diseases. Cancer cells are reported to escape the apoptotic cell suicide through the mediation of various genetic and epigenetic alterations. Consequently, agents which can induce apoptotic cascade in the cancer cells are thought to be promising anti-cancer chemotherapeutic agents (Klein, 2004; Lee, 1999).

Leukemia is reported to arise from the dysfunction of the hematopoietic cells in bone marrow due to disparities of intracellular DNA molecules. The excessive formation of immature leucocytes obstructs various other functions of the bone marrow and as a result the count of normal blood cells decreases significantly. Among all pediatric cancers, the prevalence and mortality of leukemia as a malignant disorder ranks first. Leukemia cells can easily migrate to other parts of the body including central nervous system, spleen, lymph nodes, liver etc (Mardiros et al., 2013).

DNA variations in bone marrow cells caused due to the over-exposure to radiations and certain chemical carcinogens has been reported to be the main cause of leukemia (Joshi et al., 2014). The four major classes of leukemia have been reported namely lymphoblastic leukemia, chronic lymphocytic leukemia, chronic myeloid leukemia and acute myeloid leukemia (Vardimanet al., 2009).

The treatment required for leukemia involves individual therapeutic options like chemotherapy, radiotherapy or both in combination. Bone marrow transplants, targeted therapy as well as palliative or supportive care are also required in some cases. It must 
be highlighted here that most cases of leukemia are treated by using chemotherapeutic drugs mostly they are combined into a multidrug dose therapy (Hoffbrand et al., 2006). Presently, the development of multidrug resistance by the leukemia cancer cells is the principal reason for chemotherapeutic treatment failure. Drug resistance indicates the non-susceptible nature of leukemia cells towards chemotherapeutic drugs (Badura et al., 2013). As such there is an imperative need for designing and development of novel anticancer agents which can target even drug resistant cancer cells and simultaneously are less toxic to normal cells. The main objective of the present research work was to assess the anti-cancer effects of 5methoxyhydnocarpin (Figure 1) in THP-1 human

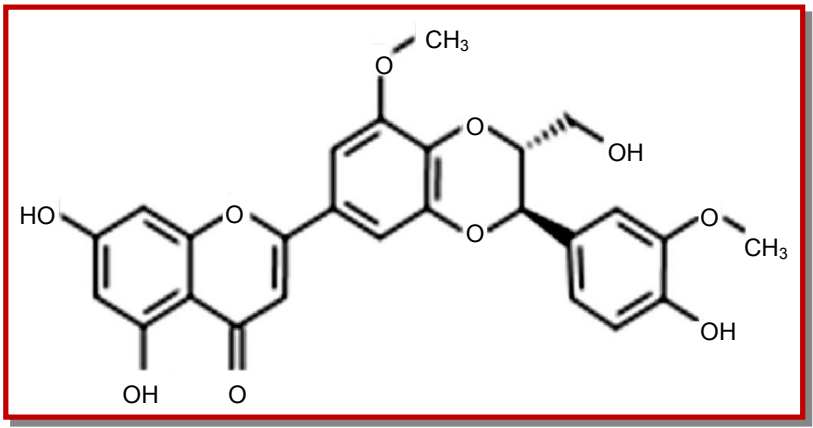

Figure 1: Chemical structure of 5-methoxyhydnocarpin (5$\mathrm{MHC})$

leukemia cancer cells and also study its effects on apoptosis induction, mitochondrial disruption, inhibition of cell migration and invasion and cell cycle arrest.

\section{Materials and Methods}

\section{Chemicals and other related reagents}

5-Methoxyhydnocarpin (5-MHC) (purity $\geq 98 \%$, obtain-

\section{Box 1: Colony formation assay (Clonogenic assay)}

\section{Principle}

Colony formation assay is a cell survival assay based on the ability of a single cell to grow into a colony. It is used to determine the effectiveness of cytotoxic agent.

\section{Requirements}

Human leukemia cancer cells (THP-1), microscope, laminar flow hood, imaging software, crystal violet, phosphate buffer solution, 5-methoxyhydnocarpin

\section{Procedure}

Step 1: Cells at the exponential growth phase were harvested and counted with the help of a hemocytometer. Cells (500 cells/well) were seeded and incubated for 12 hours and finally ed from HPLC analysis) and 3-(4,5-dimethylthiazol-2yl)-2,5-diphenyltetrazolium-bromide (MTT) were procured from Sigma-Aldrich (USA). 5-MHC was dissolved in dimethyl sulfoxide (DMSO) to make a stock solution at concentration of $100 \mathrm{mM}$, which was further diluted to a desired concentration with culture medium prior to each experiment. An equivalent volume of DMSO in complete culture medium was taken as the vehicle control. To eliminate the cytotoxicity of DMSO, the final concentration of DMSO for all experiments was kept at less than $0.2 \%$. Minimum Essential Medium and RPMI, fetal bovine serum, penicillin, streptomycin and trypsin. Phosphatebuffered saline with calcium chloride and magnesium chloride were purchased from Hangzhou Sijiqing Biological Engineering Materials Co., Ltd. (Hangzhou, China). Propidium iodide and annexin V-FITC were purchased from Boster Biological Technology Co., Ltd. (Wuhan, China).

\section{Cell line and culture conditions}

The THP-1 human leukemia cancer cell was purchased from Institute of Biochemistry and Cell Biology, Shanghai Institute for Biological Sciences, Chinese Academy of Sciences. These cells were cultured in Minimum Essential Medium and RPMI complemented with $10 \%$ (v/v) Fetal bovine serum under moisten atmosphere of $5 \% \mathrm{CO}_{2}$ at $37^{\circ} \mathrm{C}$. The medium was replaced after 3 days. Cells were sub-cultured after 3 days interval.

\section{MTT cell proliferation assay}

Human leukemia cancer cells (THP-1) were seeded at a density of $2 \times 10^{5}$ cells per well in a 96-well culture plates. 5-MHC was dissolved in DMSO at various concentrations $(0,5,10,20,40,80$ and $200 \mu \mathrm{M})$ before treating the cells with it. Then before addition of MTT solution into each well, the cells were incubated for 24, 48 and 72 hours time intervals. The supernatant was removed and supplemented with $100 \mu \mathrm{L}$ DMSO. The

treated with different prescribed amounts $(0,10,80$ and 200 $\mu \mathrm{M})$ of 5-MHC. The media was taken out (Video Clip)

Step 2: Cells were washed with phosphate buffer solution (Video Clip)

Step 3: Cells were fixed with methanol: acetic acid (Video Clip)

Step 4: After removing the fixative, incubated for 5 min (Video Clip)

Step 5: Add crystal violet for staining the cells (Video Clip)

Step 6: Wash the cells with tap water (Video Clip)

Step 7: Observe the colonies (Video clip)

References

Iv et al., 2015; Rafehi et al. 2011 
number of feasible cells is proportional to the amount of formazan crystals which were dissolved in ethanol and microplate reader was used to measure the optical density (Bio-Rad, USA) at a wavelength of $570 \mathrm{~nm}$ (Tang et al., 2015).

\section{Cell morphological evaluation by phase contrast microscopy}

THP-1 human leukemia cancer cells were seeded in 6well plates at a density of $2 \times 10^{5}$ cells $/ \mathrm{mL}$ and then cultured for 24 hours. Afterwards, the cells were treated with several concentrations of 5-MHC $(0,10,80$ and 200 $\mu \mathrm{M})$ for 48 hours. Following to drug treatment, culture plates were monitored with the help of inverted phase contrast microscope (Olympus, Japan) and photographs were captured. DMSO was used as a negative control.

\section{Cell cycle analysis by flow cytometry}

Human leukemia cancer cells (THP-1) were seeded at a density of $2 \times 10^{5}$ cells $/ \mathrm{mL}$ into a 6 -well plates and incubated for 48 hours for total cell attachment. The cells were indulged with different doses $(0,10,80$ and $200 \mu \mathrm{M})$ of 5-MHC for 48 hours. The cells were harvested by trypsinization, centrifuged at 12,000 rpm for $20 \mathrm{~min}$, washed with PBS twice and then set with ice -cold $70 \%$ ethanol at $-20^{\circ} \mathrm{C}$ for 1 hour. After the cells began to resuspended in $400 \mu \mathrm{L}$ of PBS, $50 \mu \mathrm{L}$ PI and 50 $\mu \mathrm{L}$ RNase A, the cells were finally examined on a FACS Calibur flow cytometer (Becton, Dickinson and Company, USA). Data on 20,000 cells were attained and processed with Cell Quest software.
Quantification of cell apoptosis by annexin V-FITC assay

Human leukemia cancer cells (THP-1) at a density of $2 x$ $10^{5}$ cells $/ \mathrm{mL}$ were seeded into 12-well plates and incubated for 12 hours. After treating cells with different doses $(0,10,80$ and $200 \mu \mathrm{M})$ of 5-MHC, these cells were washed with PBS and then resuspended in binding buffer containing annexin V-fluorescein isothiocyanate and propidium iodide for $30 \mathrm{~min}$. Cells grown in media containing an equivalent amount of $0.35 \%$ DMSO without any control drug. Fluorescence intensity was observed by using flow cytometry (Becton, Dickinson and Company, Franklin Lakes, NJ, USA).

\section{In vitro wound healing assay}

This assay was carried out as per a reported standard method (Liang et al., 2007). Human leukemia cells ( $2 \mathrm{x}$ $10^{5}$ cells $/ \mathrm{mL}$ ) were seeded in a 6-well plates and incubated at $37^{\circ} \mathrm{C}$ until 95 to $100 \%$ full confluent monolayer was achieved. Following 12 hours of starvation, a $50 \mathrm{~mL}$ pipette tip was used to create a straight cell-free wound. Each well was washed twice with PBS to remove any debris and then treated with different concentrations of 5-MHC $(0,5,10,20,40,80$ and $200 \mu \mathrm{M}$ ) in a medium. After 48 hours of incubation, the cells were fixed and decolorized with $5 \%$ ethanol containing $1.2 \%$ crystal violet powder for $20 \mathrm{~min}$, and haphazardly selected fields were photographed under a light microscope. The number of cells that migrated into the damaged area was counted.

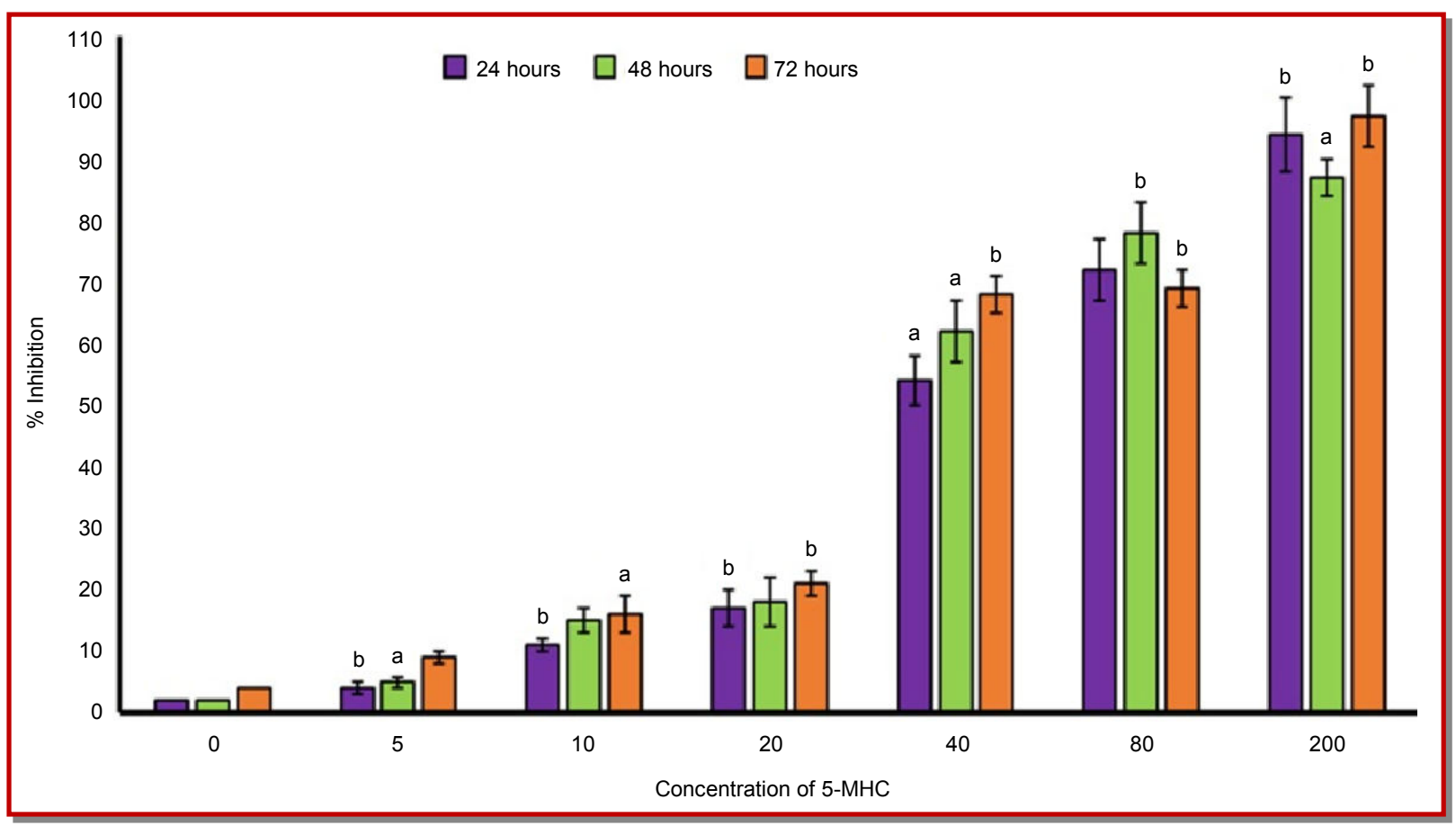

Figure 2: Dose- and time-dependent anti-tumor effects of 5-methoxyhydnocarpin (5-MHC) in human leukemia cancer cells (THP1). Data are shown as the mean $\pm S D$ of three independent experiments. ${ }^{a} p<0.05$, ${ }^{b} p<0.01$ vs $0 \mu \mathrm{M}$ (control) 


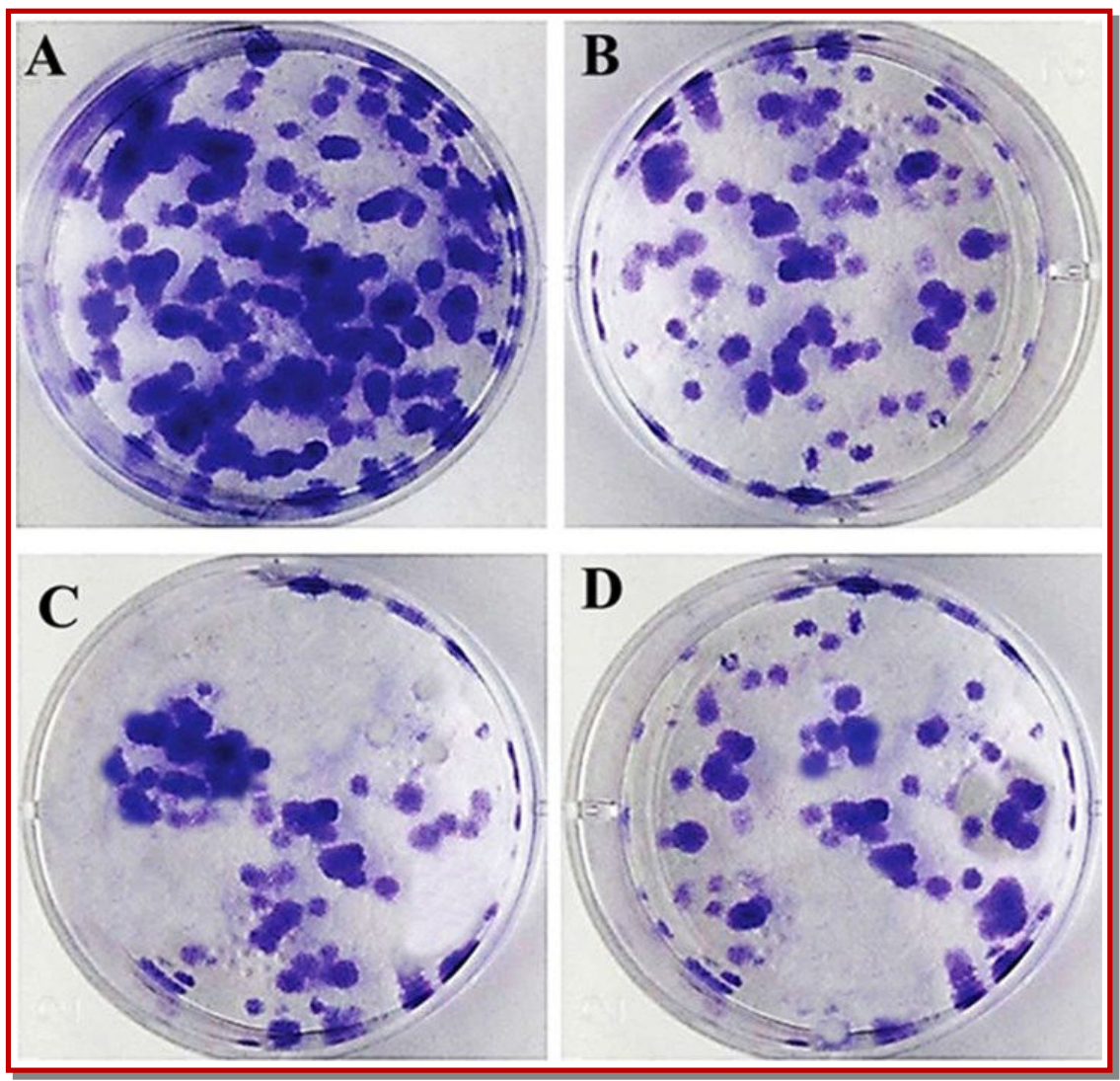

Figure 3: The inhibitory effect of 5-MHC on the colony formation affinity of THP-1 human leukemia cancer cells. The figure shows the representative images of colony-forming assay using light microscope. The cells were treated without (A) and with 10 (B), 80 (C) and 200 (D) $\mu \mathrm{M}$ dose of 5-MHC

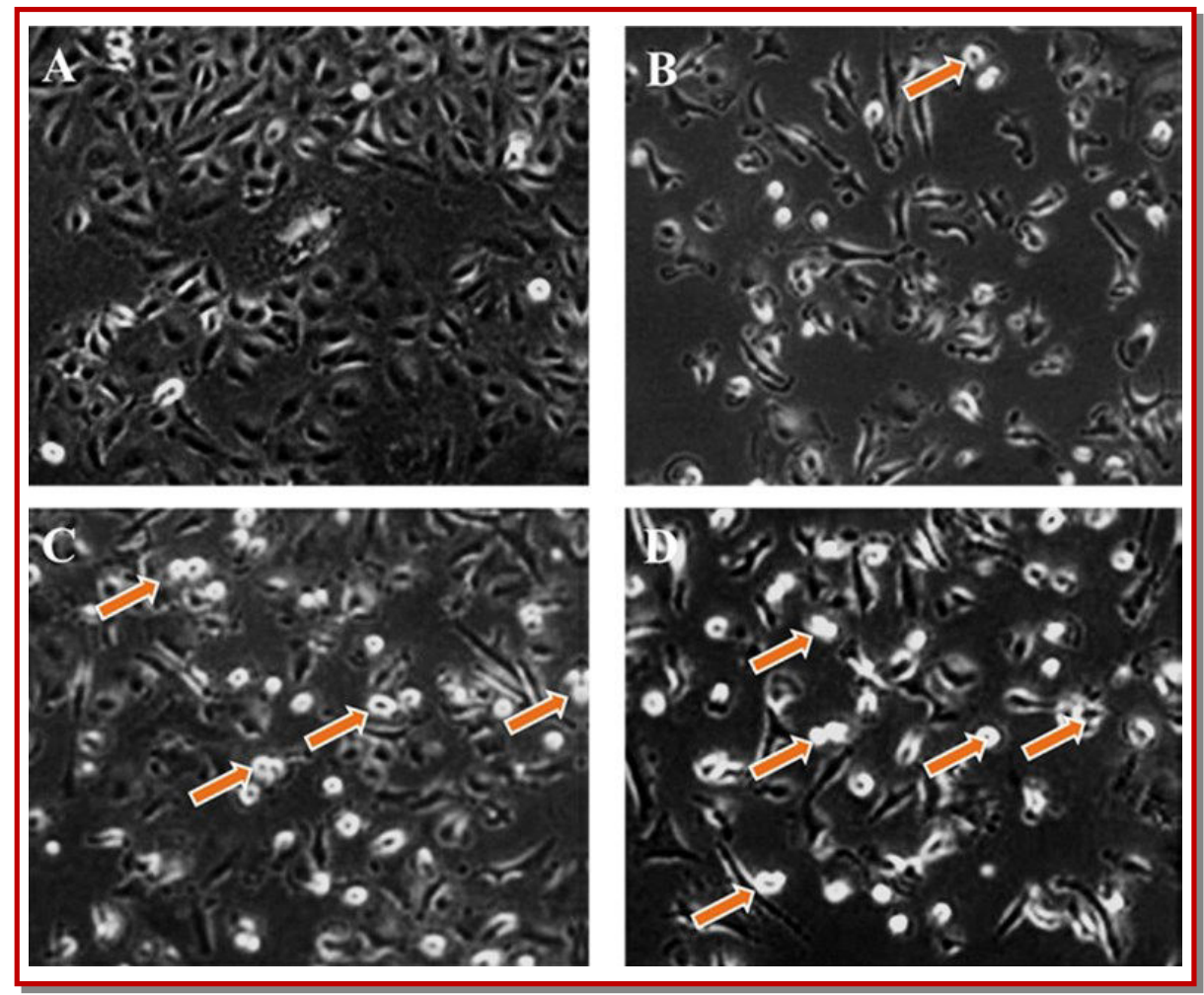

Figure 4: Effect of 5-MHC on the cell viability of THP-1 human leukemia cancer cells. Phase contrast microscopic images of the 5MHC-treated cells at different doses viz., 0 (A), 10 (B), 80 (C) and 200 (D) $\mu \mathrm{M}$ for 48 hours 


\section{Statistical analysis}

All the data were expressed as mean \pm standard error of mean (SEM). The importance of difference between groups was estimated by one-way analysis of variance (ANOVA) followed by Dunnett's post-hoc test. Differences were considered statistically significant a $\mathrm{p}<0.05, \mathrm{p}<0.01$.

\section{Results}

Anti-tumor activity of 5-methoxyhydnocarpin (5MHC) in THP-1 human leukemia cancer cells

MTT cell viability assay was used to assess the anti- tumor effects of 5-MHC at various doses as well as at various incubation times (Figure 2). The results indicated that 5-MHC provoked dose-dependent as well as time-dependent cytotoxic effects in THP-1 human leukemia cancer cells. The strength of the compound was determined and expressed as $\mathrm{IC}_{50}$ values which are a measure of the efficiency of a drug. The $\mathrm{IC}_{50}$ values at 24,48 and 72 hours time intervals for the compound were found to be $37.5,26.6$ and $18.4 \mu \mathrm{M}$ respectively.

5-Methoxyhydnocarpin inhibited the colony forming affinity of THP-1 leukemia cancer cells

The effect of 5-MHC on the colony forming ability in THP-1 human leukemia cancer cells is shown in Figure
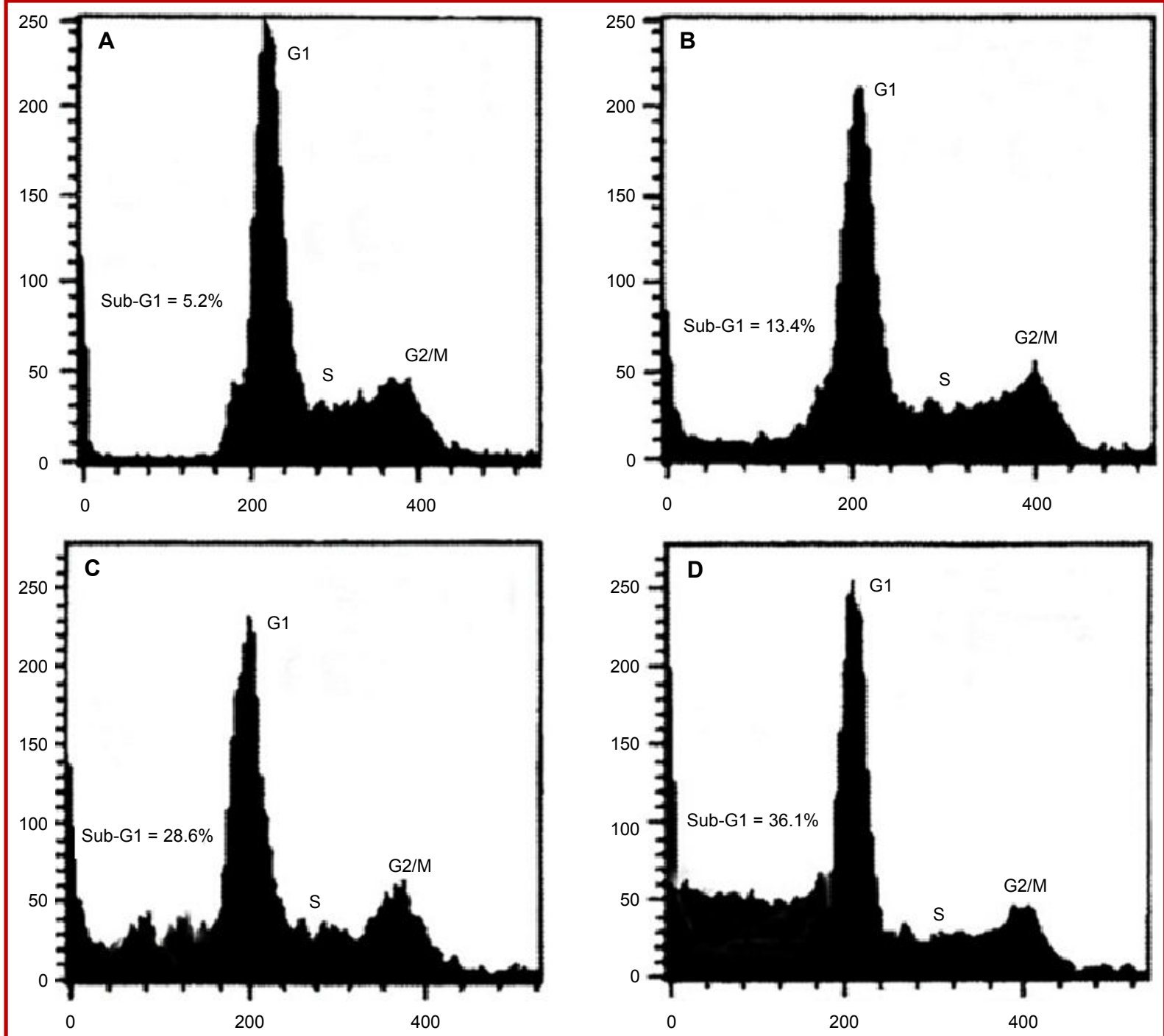

Figure 5: Effect of 5-methoxyhydnocarpin on the cell cycle phase distribution in THP-1 human leukemia cancer cells. The cells were treated without (A) and with 10 (B), 80 (C) and 200 (D) $\mu \mathrm{M}$ dose of 5-methoxyhydnocarpin for 48 hours and then observed by flow cytometry. Sub-G1 cell population increased from $5.2 \%$ in untreated control to $13.4 \%, 28.6 \%$ and $36.1 \%$ in groups treated with 10, 80 and $200 \mu \mathrm{M}$ dose of 5-methoxyhydnocarpin respectively 


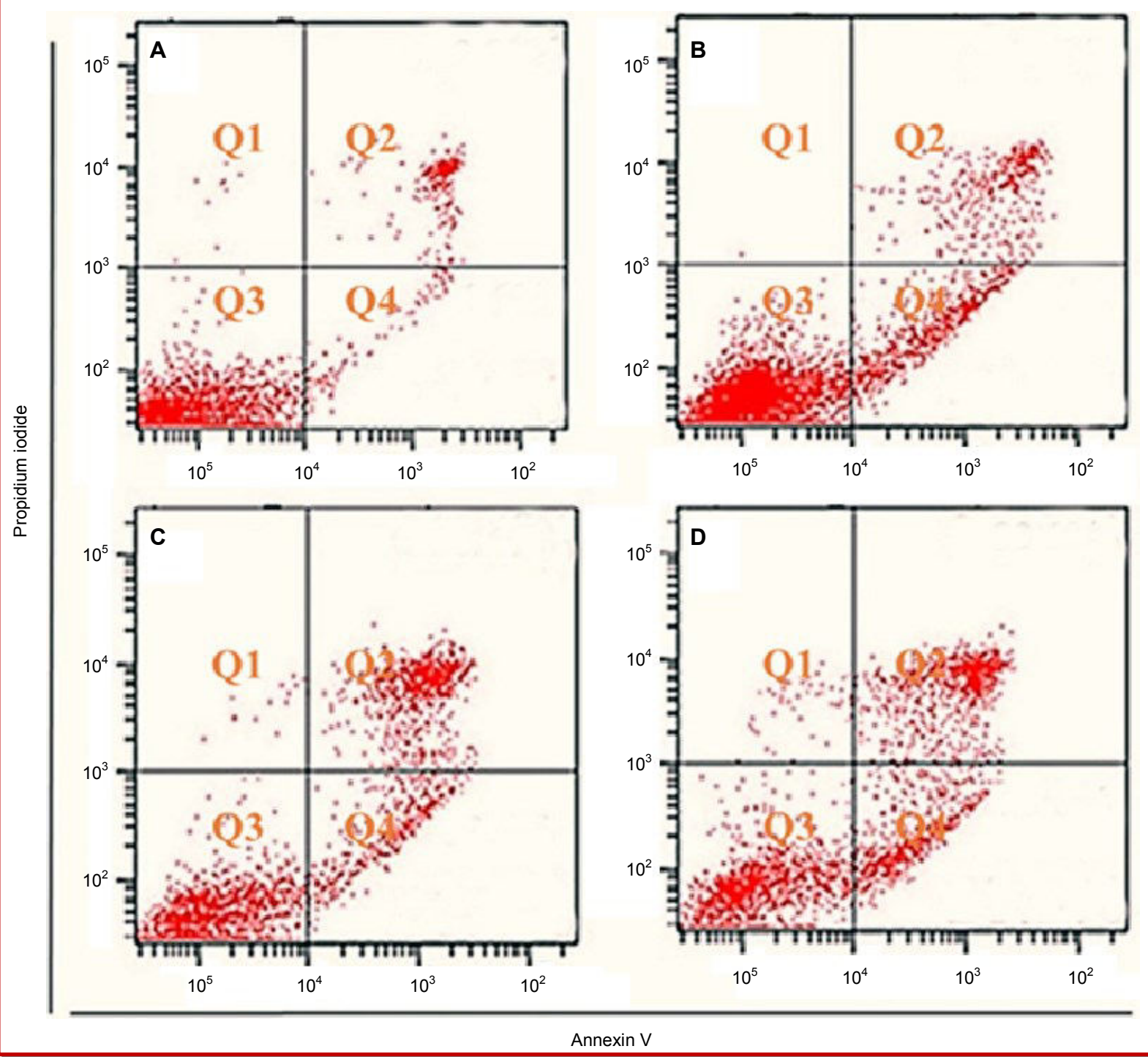

Figure 6: Quantification of apoptosis in THP-1 human leukemia cells by using annexin V-FITC assay and flow cytometry. The cells were treated without (A) and with 10 (B), 80 (C) and 200 (D) $\mu \mathrm{M}$ doses of 5-methoxyhydnocarpin respectively and then observed using flow cytometry

3. 5-MHC inhibited the clone formation activity (colonogenic) of the THP-1 human leukemia cancer cells by suppressing the number of tumor forming cell colonies which also showed dose-dependence. Thus MTT and clonogenic assays indicate that 5-MHC has both anti-proliferative and anti-clonogenic properties. These two properties can make this compound a promising anti-cancer agent.

5-MHC induces significant loss of cell viability and change in cell morphology in THP-1 cells

In this assay, the 5-MHC-induced morphological changes in THP-1 cells were observed under a phase contrast microscope. As can be seen from Figure 4A-D, in comparison to the control unprocessed cells, the 5MHC-treated cells at 10 (B), 80 (C) and 200 (D) $\mu \mathrm{M}$ dose -exhibited visible signs of morphological changes including rounding and withering of cells with unorganized cell layers. The cells became disconnected from one another and freely floated in the medium.

\section{5-Methoxyhydnocarpin induces sub-G1 cell cycle arrest}

With the help of flow cytometry along with propidium iodide as fluorescent probe specified that 5methoxyhydnocarpin had a deep impact on cell cycle in THP-1 human leukemia carcinoma cells. 5Methoxyhydnocarpin induced sub-G1 cell cycle arrest in a dose-dependent manner. In comparison to the control cells (Figure 5A no drug treatment) which didn't expressed any indications of apoptotic cells, the 5 -methoxyhydnocarpin treated cells with 10, 80 and 200 $\mu \mathrm{M}$ dose led to enhancement of sub-G1 cells from 13.4 


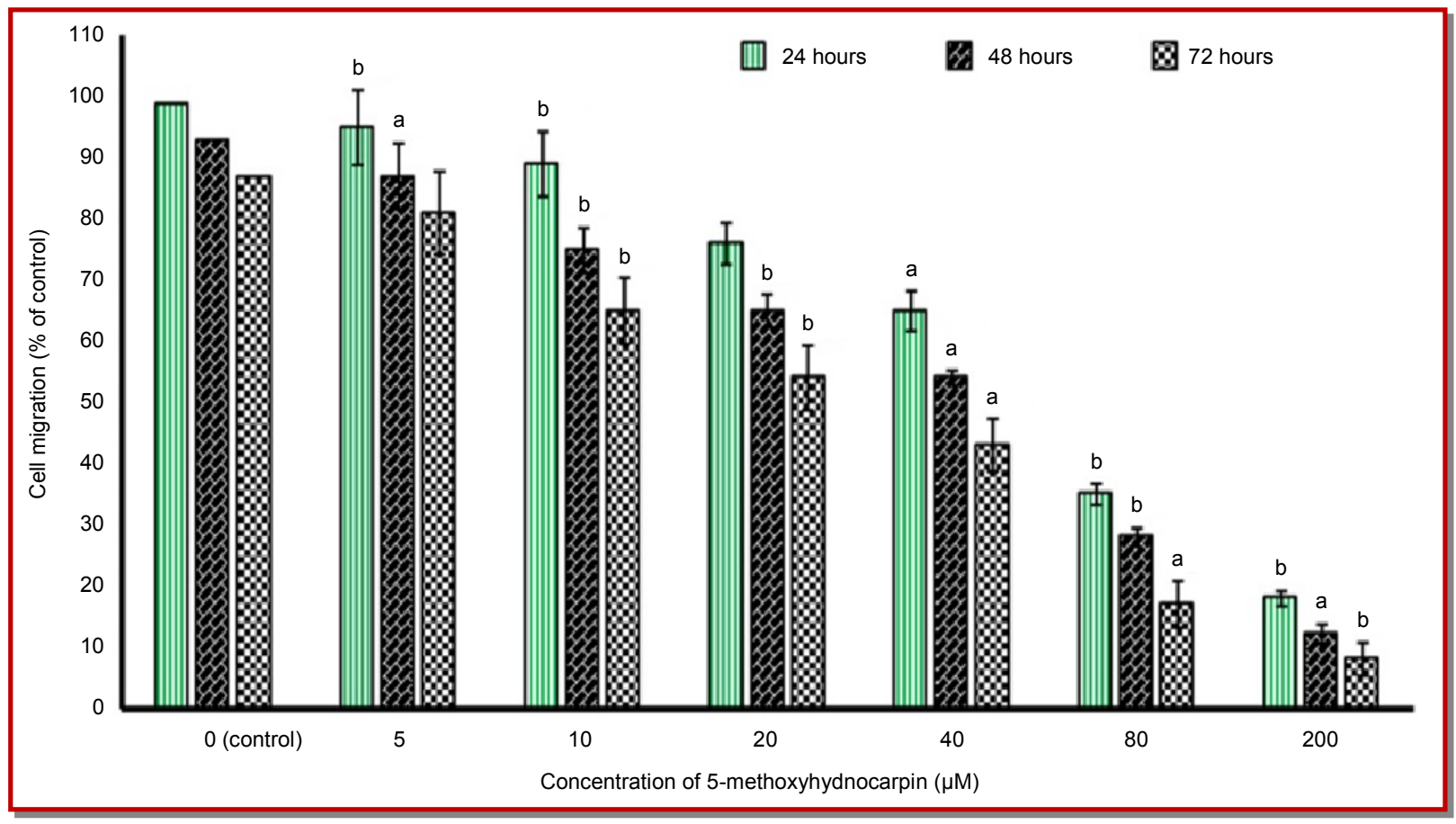

Figure 7: 5-methoxyhydnocarpin-induced reduction in the migration of THP-1 human leukemia cells. Data are shown as the mean \pm SD of three independent experiments. ap $<0.05$, bp $<0.01$ vs $0 \mu \mathrm{M}$ (control). The compound induced dose-dependent as well as time-dependent cell migration inhibition

to 28.6 and $36.1 \%$ respectively (Figure 5B-D, drug treatment).

\section{5-Methoxyhydnocarpin induced early and late apop- tosis in THP-1 human leukemia cells}

To confirm the apoptotic cell death caused by 5 methoxyhydnocarpin in THP-1 human leukemia cells, annexin-V FITC assay for apoptosis quantification was used including flow cytometry as well. The results indicated that 5-methoxyhydnocarpin could cause both early and late apoptotic actions in these cancer cells. In contrast to the control cells, which showed only $6.7 \%$ cells to be apoptotic, 5-methoxyhydnocarpin treated cells at 10, 80 and $200 \mu \mathrm{M}$ dose induced significant apoptosis with percentage of apoptotic cells increasing from 19.5, 36.5 and 52.8\% respectively (Figure 6A-D). The four quadrants Q1, Q2, Q3 and Q4 represent necrotic cells, late apoptotic cells, viable cells and early apoptotic cell population respectively.

5-Methoxyhydnocarpin induced dose- and timedependent inhibition of cell migration

Cell migration along with cell invasion are the two key aspects of tumor cells which play major role cancer metastasis and cancer progression. To further investigate the mode of action of 5-methoxyhydnocarpin in THP-1 human leukemia cells, its effect on cell migration was evaluated by using in vitro wound healing assay. The results are graphically shown in Figure 7 and indicate that 5-methoxy-hydnocarpin is a strong inhibitor of cancer cell migration. It showed inhibition of cell migration not only in a dosedependent manner but also in a time-dependent manner.

\section{Discussion}

In current study, the anti-tumor effects of 5methoxyhydnocarpin were evaluated against THP-1 human leukemia cancer cells. MTT assay was used to evaluate the cytotoxic effects while as the clonogenic assay was used to determine the effect of the compound on colony formation tendency of THP-1 cells. The results showed that 5-methoxyhydnocarpin induces considerable cytotoxic effects in THP-1 cancer cells. The compound also inhibits colony formation ability of these cells in a dose-dependent manner. Both of these results confirm that 5-methoxyhydnocarpin have got anchorage-dependent as well as anchorage-independent cytotoxic effects in THP-1 cancer cells. Further, on using phase contrast microscopy, changes in THP-1 cellular morphological were monitored after the cells were treated with different doses of 5-methoxyhydnocarpin. After treatment of these cells, they became rounded and shrunken with unorganized cell layers.

The effects of 5-methoxyhydnocarpin on the cell cycle phase distribution were assessed by flow cytometry using propidium iodide as a fluorescent probe. These results indicated that 5-methoxyhydnocarpin targeted 
sub-G1 phase of the cell cycle. In comparison to the control cells which didn't showed any clues of apoptotic cells, the 5-methoxyhydnocarpin treated cells with 10, 80 and $200 \mu \mathrm{M}$ dose led to enhancement of subG1 cells from 13.4 to $28.6 \%$ and then up to $36.1 \%$ respectively. In addition, the effect of 5-methoxyhydnocarpin on the early and late apoptotic processes was evaluated by using annexin-V FITC assay in combination with flow cytometry. This assay is used for quantification of the apoptosis and indicated that 5methoxyhydnocarpin could cause both early and late apoptotic events in these cancer cells. In contrast to the control cells, which showed only $6.7 \%$ cells to be apoptotic, 5-methoxyhydnocarpin treated cells at 10, 80 and $200 \mu \mathrm{M}$ dose-induced significant apoptosis with percentage of apoptotic cells increasing from 19.5, 36.5 and $52.8 \%$ respectively. Finally, the effects of 5methoxyhydnocarpin on the cell migration capability of THP-1 cells were evaluated by in vitro wound healing assay. The results showed that 5-methoxyhydnocarpin is a powerful inhibitor of cancer cell migration. It showed suppression of cell migration not only in a dose -dependent manner but also in a time-dependent fashion.

Spread of cancerous cells in the body involves a series of steps by which these cancer cells invade neighboring cells, blood or lymphatic vessels, rendering them to move to distant organs and create new metastatic colonies of these cancer cells. It has been reported that metastasis is a primary cause of cancer-related deaths. Cell migration and cell invasion are two such processes by which tumors become metastatic in patients (Yamaguchi et al., 2005; Bozzuto et al., 2010). Inhibiting cell invasion and cell migration constitutes an important therapeutic target in cancer treatment (Price and Thompson, 2002). Compounds targeting metastasis are promising anti-cancer candidates and this approach constitutes a novel method of cancer treatment. Such compounds are expected to inhibit cell invasion and cell migration with little or no cytotoxicity (Kohn and Liotta, 1995). Our results show that 5-methoxyhydnocarpin is a powerful inhibitor of cell migration in THP-1 human leukemia cancer cells. Apoptosis is a highly specialized biochemical mechanism by the help of which multicellular organisms get divest of the abnormal or damaged cells. The apoptotic cells can be easily differentiated from the normal cells from their characteristic morphological features including membrane blebbing, cell shrinkage as well as from their molecular expressions ( $\mathrm{Hu}$ and Kavanagh, 2003; Lin et al., 2007; Doonan and Cotter, 2008). 5-Methoxyhydnocarpin was shown to induce significant apoptosis in THP-1 cells.

\section{Conclusion}

5-Methoxyhydnocarpin induces anti-tumor effects in
THP-1 human leukemia cells by inducing early and late apoptosis, sub-G1 cell cycle arrest and inhibition of cancer cell migration.

\section{Conflict of Interest}

The authors declare that there is no conflict of interest to reveal.

\section{References}

Badura S, Tesanovic T, Pfeifer H, Wystub S, Nijmeijer BA, Liebermann M, Falkenburg JH, Ruthardt M, Ottmann OG. Differential effects of selective inhibitors targeting the PI3K/ AKT/mTOR pathway in acute lymphoblastic leukemia. PLoS One. 2013; 11: e80070.

Bozzuto G, Ruggieri P, Molinari A. Molecular aspects of tumor cell migration and invasion. Ann Ist Super Sanita. 2010; 46: 66-80.

Doonan F, Cotter TG. Morphological assessment of apoptosis. Methods. 2008; 44: 200-04.

Hoffbrand AV, Moss PAH, Pettit JE. Essential haematology, Blackwell. 5th ed., 2006.

$\mathrm{Hu} \mathrm{W}$, Kavanagh JJ. Anti-cancer therapy targeting the apoptotic pathway. Lancet Oncol. 2003; 4: 721-29.

lv J, Cao MQ, Yu JC. Alantolactone pyrazoline analogue inhibits cancer cell proliferation and induces apoptosis in non-small cell lung carcinoma cells. Bangladesh J Pharmacol. 2015; 10: 409-15.

Joshi I, Yoshida T, Jena N, Qi X, Zhang J, Van Etten RA, Georgopoulos K. Loss of Ikaros DNA-binding function confers integrin-dependent survival on pre-B cells and progression to acute lymphoblastic leukemia. Nat Immuno. 2014; 115: 294-304.

Klein G. Cancer, apoptosis, and nonimmune surveillance. Cell Death Differ. 2004; 1: 13-17.

Kohn EC, Liotta LA. Molecular insights into cancer invasion: Strategies for prevention and intervention. Cancer Res. 1995; 55: 1856-62.

Lee KH. Anti-cancer drug design based on plant-derived natural products. J Biomed Sci. 1999; 4: 236-50.

Liang CC, Park AY, Guan JL. In vitro scratch assay: A convenient and inexpensive method for analysis of cell migration in vitro. Nat Protoc. 2007; 2: 329-33.

Lin JC, Ho YS, Lee JJ, Liu CL, Yang TL, Wu CH. Induction of apoptosis and cell-cycle arrest in human colon cancer cells by meclizine. Food Chem Toxicol. 2007; 45: 935-44.

Mardiros A, Brown CE, Budde LE, Wang X, Forman SJ. Acute myeloid leukemia therapeutics: CARs in the driver's seat. Oncoimmunology 2013; 12: e27214.

Price JT, Thompson EW. Mechanisms of tumour invasion and metastasis: Emerging targets for therapy. Expert Opin Ther Targets. 2002; 6: 217-33.

Rafehi H, Orlowski C, Georgiadis GT, Ververis K, El-Osta A, 
Tang J, Zhao JJ, Li ZH. Ethanol extract of Artemisia sieversiana exhibits anticancer effects and induces apoptosis through a mitochondrial pathway involving DNA damage in COLO205 colon carcinoma cells. Bangladesh J Pharmacol. 2015; 10: $518-23$.

Vardiman JW, Thiele J, Arber DA, Brunning RD, Borowitz MJ, Porwit A, Harris NL, Le Beau MM, Hellström-Lindberg E,
Tefferi A, Bloomfield CD. The 2008 revision of the World Health Organization classification of myeloid neoplasms and acute leukemia: Rationale and important changes. Blood. 2009; 114: 937-51.

Yamaguchi H, Wyckoff J, Condeelis J. Cell migration in tumors. Curr Opin Cell Biol. 2005; 17: 559-64.

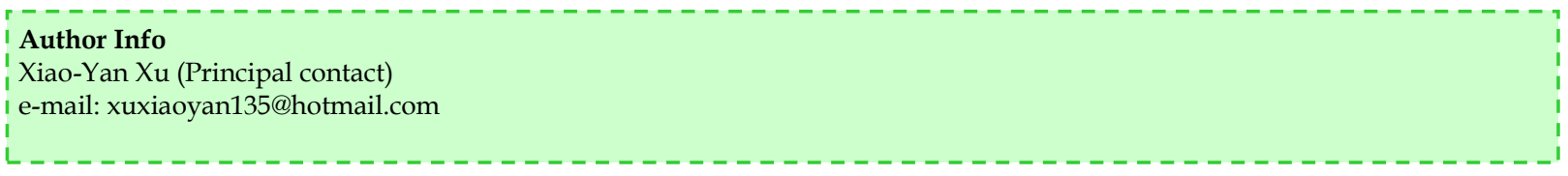




\section{Your feedback about this paper}

1. Number of times you have read this paper 0

2. Number of times you have seen the video clip 0

3. Quality of paper Click

4. Your comments

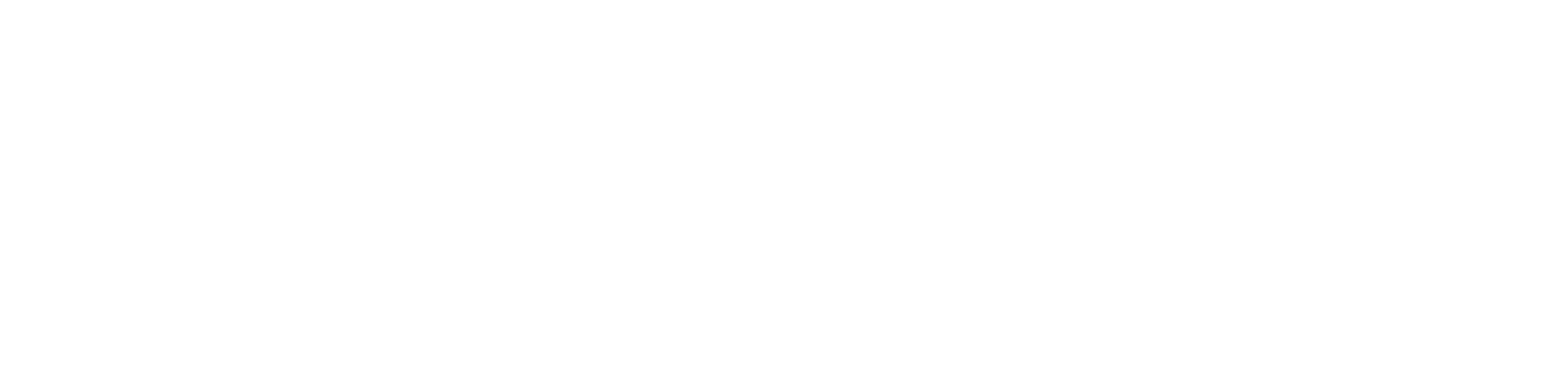

